\title{
Longitudinal dependence of middle and low latitude zonal plasma drifts measured by DE-2
}

\author{
J. W. Jensen and B. G. Fejer \\ Center for Atmospheric and Space Sciences, Utah State University, Logan, UT 84322-4405, USA
}

Received: 18 May 2007 - Revised: 16 November 2007 - Accepted: 4 December 2007 - Published: 2 January 2008

\begin{abstract}
We used ion drift observations from the DE-2 satellite to study for the first time the longitudinal variations of middle and low latitude $F$ region zonal plasma drifts during quiet and disturbed conditions. The quiet-time middle latitude drifts are predominantly westward; the low latitude drifts are westward during the day and eastward at night. The daytime quiet-time drifts do not change much with longitude; the nighttime drifts have strong season dependent longitudinal variations. In the dusk-premidnight period, the equinoctial middle latitude westward drifts are smallest in the European sector and the low latitude eastward drifts are largest in the American-Pacific sector. The longitudinal variations of the late night-early morning drifts during June and December solstice are anti-correlated. During geomagnetically active times, there are large westward perturbation drifts in the late afternoon-early night sector at upper middle latitudes, and in the midnight sector at low latitudes. The largest westward disturbed drifts during equinox occur in European sector, and the smallest in the Pacific region. These results suggest that during equinox SAPS events occur most often at European longitudes. The low latitude perturbation drifts do not show significant longitudinal dependence.
\end{abstract}

Keywords. Ionosphere (Electric fields andcurrents; Ionospheric disturbances; Mid-latitude ionosphere)

\section{Introduction}

Ionospheric plasma drifts perpendicular to the Earth's magnetic field are driven by $\mathrm{E}$ and $\mathrm{F}$ region dynamo electric fields during geomagnetically quiet times, and also by solar wind-magnetospheric and ionospheric disturbance dynamo electric fields during periods of enhanced geomagnetic activity (e.g. Blanc and Richmond, 1980; Kelley, 1989; Rich-

Correspondence to: B. G. Fejer

(bfejer@cc.usu.edu) mond, 1995; Fejer, 1997). Since these plasma drifts (electric fields) play important roles on the distribution of ionization from middle to equatorial latitudes, the understanding of their driving mechanisms and spatial and temporal variations is essential for the development and validation of realistic models of the ionospheric weather. In this study, we focus on the global characteristics of $\mathrm{F}$ region zonal drifts.

Middle and low latitude ionospheric zonal plasma drifts have been routinely been measured with incoherent radar observations from Millstone Hill $\left(42.6^{\circ} \mathrm{N}, 66.5^{\circ} \mathrm{W}\right.$; invariant latitude $\left.54^{\circ}\right)$, Saint-Santin $\left(45^{\circ} \mathrm{N}, 2^{\circ} \mathrm{E}\right.$; invariant latitude $\left.44^{\circ}\right)$, Arecibo $\left(18^{\circ} \mathrm{N}, 67^{\circ} \mathrm{W}\right.$, invariant latitude $\left.34^{\circ}\right)$, Shigaraki $\left(34.9^{\circ} \mathrm{N}, 136.1^{\circ} \mathrm{E}\right.$, invariant latitude $\left.33^{\circ}\right)$, and Jicamarca $\left(11.9^{\circ} \mathrm{S}, 76.8^{\circ} \mathrm{W}\right.$; dip latitude $\left.1^{\circ} \mathrm{N}\right)$. These measurements have determined the local time, season, solar cycle, and magnetic activity dependent climatologies of the zonal plasma drifts over the regions sampled by the radars (e.g., Blanc, 1983; Fukao et al. 1991; Fejer, 1991, 1993, 1997; Oliver et al., 1993; Takami et al., 1996; Fejer et al., 2005; Buonsanto and Witasse, 1999; Scherliess et al., 2001; Foster et al., 2002). At equatorial latitudes, nighttime zonal drifts have also been frequently studied with zonal drift measurements of ionospheric plasma irregularities using groundbased spaced receiver and optical imaging techniques (e.g., Sobral et al., 1999; Martinis et al., 2003; Sheehan and Valladares et al., 2004).

Global F region zonal plasma drifts have been studied using ion drift meter (IDM) measurements on board of the polar orbiting Dynamics Explorer-2 (DE-2) satellite. Coley and Heelis (1989) used DE-2 data to study the local time and altitudinal variations of low latitude zonal drifts. Heelis and Coley (1992) determined the average middle and low latitude DE-2 zonal drift patterns during quiet and magnetically disturbed conditions, and studied their dependence on dynamo and high latitude electric fields. Coley et al. (1994) used DE-2 IDM and wind and temperature spectrometer (WATS) data to show that both the superrotation and the

Published by Copernicus Publications on behalf of the European Geosciences Union. 
diurnal components of ion and neutral zonal velocities flows are strongly peaked at the dip equator. Scherliess and Fejer (1998) and Fejer and Scherliess (1998) determined the average response of middle latitude DE-2 zonal drifts to prompt penetration and disturbance dynamo electric fields during moderately disturbed conditions. They also showed that these perturbation drift patterns are in good agreement with results from incoherent scatter radar measurements and global convection models.

There have been only a few studies of the longitudinal variation of the ambient quiet-time $\mathrm{F}$ region zonal drifts. Fejer (1993) and Takami et al. (1996) have discussed the relationship of the $\mathrm{F}$ region drift velocities over Arecibo and over the MU radar at Shigaraki. Immel et al. (2004) showed that the zonal drifts of nighttime equatorial plasma depletions observed on board the high apogee IMAGE satellite during March-May 2002 were largest in the Indian sector. Fejer et al. (2005) suggested that longitudinal variation of the equatorial $\mathrm{F}$ region zonal drifts in the dusk-premidnight sector should be strongly controlled by the season dependent prerversal enhancement of the vertical plasma drifts.

Satellite and incoherent radar observations at subauroral and middle latitudes during strongly enhanced geomagnetic conditions have shown the occurrence of very strong, highly localized, northward electric fields (westward ion drifts) are due to the extension of the auroral zone to lower latitudes and the formation of very large polarization electric fields near the equatorward extent of the pre-midnight sunward convection (e.g., Galperin et al., 1974, 1997; Burke et al., 2000; Anderson et al., 2001; Foster and Vo, 2002). These large electric fields generate large highly structured storm enhanced plasma densities, steep spatial gradients in plasma parameters, strong radio wave scintillations, and they strongly affect the erosion and reconfiguration of the outer plasmasphere (e.g., Foster et al., 2002). The subauroral regions of large $(>500 \mathrm{~m} / \mathrm{s})$ westward convection has recently been named Subauroral Polarization Streams (SAPS) (Foster and Burke, 2002). The longitudinal distribution of these large westward zonal drifts has not been determined.

In this work we use entire database of middle to equatorial latitudes DE-2 observations to study, for the first time, the longitudinal dependence of the ionospheric zonal plasma drifts. In the next sections, we first briefly describe the IDM (Ion Drift Meter) measurements on board the DE-2 satellite and our database and methodology. Then, we describe the season and latitude dependent longitudinal variations of these plasma drifts during quiet and geomagnetically active times.

\section{Data and methodology}

The Dynamics Explorer 2 satellite was launched in August 1981 into a $90^{\circ}$ inclination orbit. This mission ended in February 1983. The apogee was near $1200 \mathrm{~km}$, and the perigee near $280 \mathrm{~km}$. The ascending node (location of the northbound equatorial crossing) passed through an entire $24 \mathrm{~h}$ period in 12 months. Therefore, local time and season were locked together. The data near dawn and dusk were measured during the summer and winter solstices, and the data near noon and midnight were obtained during the equinoxes. We have used $16 \mathrm{~s}$ averaged IDM zonal drifts. The characteristics of the instrument were described by Heelis et al. (1981). The sensitivity of the ion drift component perpendicular to the satellite track was about $5 \mathrm{~m} / \mathrm{s}$, and the absolute accuracy was about $10 \mathrm{~m} / \mathrm{s}$. Even though the instrument measured the zonal drift in the geographic east-west direction, these drifts were dominated by the geomagnetic east-west ExB ion motion (Heelis and Coley, 1992).

We have used data from the altitudinal range of 280 to $800 \mathrm{~km}$ to minimize the effects of light ions at upper altitudes. At the magnetic equator, these altitudes correspond to invariant latitudes of about $10^{\circ}$ and $20^{\circ}$, respectively. We have also restricted our data to altitudes between 400 and $800 \mathrm{~km}$ for invariant latitudes smaller than $15^{\circ}$ during 19:00 and 23:00 LT, to minimize the effects of the shear in the zonal drifts below the $\mathrm{F}$ region peak. In order to account for altitudinal variations, the drifts were mapped along the magnetic field lines to a height of $400 \mathrm{~km}$ using the procedure presented by Jacobsen et al. (1996), which assumes equipotential magnetic field lines. When ion density data were available, we restricted our database to drift measurements corresponding to densities greater than $2 \times 10^{4} \mathrm{~cm}^{-3}$. Density measurements were not available from November 1981 to February 1982 due to a malfunction of the retarding potential analyzer (RPA).

Figure 1 shows that the number of measurements in three latitudinal sectors as a function of solar local time (SLT). The total number of observations during quiet $(K p \leq 3)$ and disturbed $(K p>3)$ times was about the same, but they decreased significantly with latitude. The numbers are smallest during 00:00-04:00 LT and 12:00-16:00 LT, which correspond to solsticial periods. Only the 04:00-08:00 LT period have sufficiently large number of measurements for the reliable estimates of the hourly average drifts during two different seasons (summer and winter). Therefore, this is also the only period when we have been able to determine the longitudinal dependence of the drifts during different seasons. The $16 \mathrm{~s}$ integration time in the DE-2 polar orbit resulted in about 12 data points in a $10^{\circ}$ latitudinal range.

We have initially determined the latitudinal and local time dependence of the longitudinally averaged drifts by averaging the data in one hour and $5^{\circ}$ latitudinal bins for $\Lambda<60^{\circ}$, separately for the northern and southern hemisphere data. We have used both solar and magnetic local times in our analysis with essentially identical results. Most of our results will be presented as a function of solar local time since this allow an easier comparison with radar data; the midlatitude disturbed drifts will be shown as a function of magnetic local time. The study of seasonal, longitudinal and 
J. W. Jensen and B. G. Fejer: Longitudinal dependence of middle and low latitude zonal plasma drifts measured by DE-2553

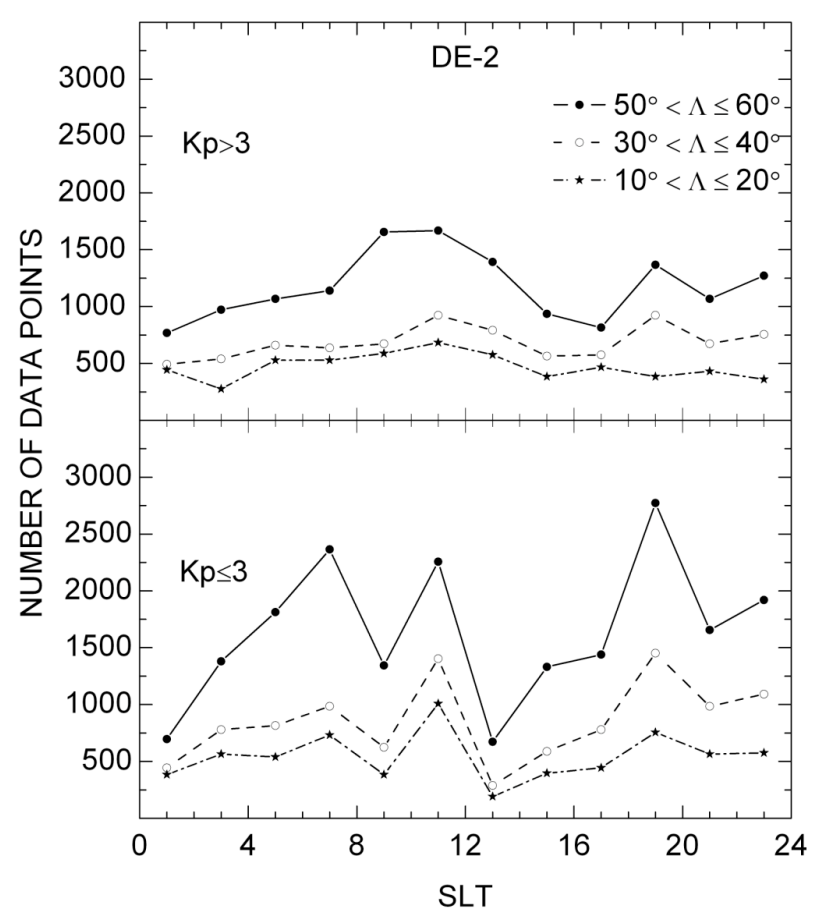

Fig. 1. Number of DE-2 zonal drift measurements in three latitudinal sectors during geomagnetically quiet and active times.

magnetic activity effects required larger temporal and spatial bins to improve statistical significance. In this case, we binned the data in six four hour periods, three four month seasons (November-February, May-August, March-April and September-October), and in $10^{\circ}$ latitudinal, and $60^{\circ}$ overlapping longitudinal bins centered $30^{\circ}$ apart, and with periodic boundary conditions.

\section{Quiet-time drifts}

In this section, we present initially the latitudinal and local time profiles of the longitudinally averaged quiet-time zonal drifts, and then examine their longitudinal dependence.

\subsection{Latitudinal and local time dependence}

Figure 2 shows the latitudinal variations of longitudinally averaged quiet-time $(K p \leq 3)$ zonal drifts. The daytime drifts are westward and have largest values (about $80 \mathrm{~m} / \mathrm{s}$ ) near noon and at low latitudes; the evening drifts are small and mostly westward except at the lowest latitudes. After sunset, they are westward at the highest latitudes, they change to eastward for $\Lambda=45^{\circ}$, and reach their peak values (about $150 \mathrm{~m} / \mathrm{s}$ ) at the lowest latitudes. The northern and southern hemisphere data are in good agreement, as expected from the conjugacy of the meridional electric fields. The results presented in Fig. 2 are in good agreement with the latitudi-
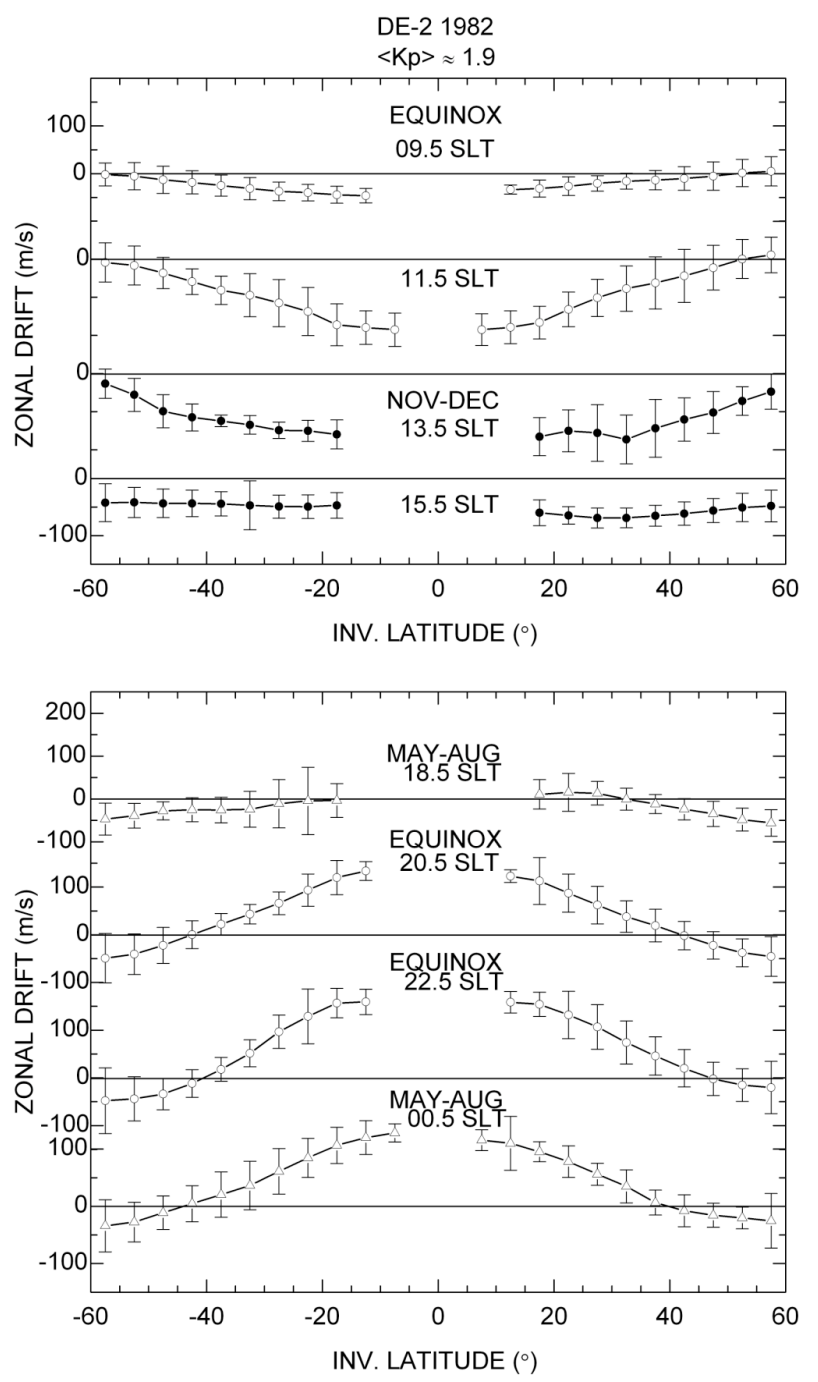

Fig. 2. Examples of latitudinal profiles of quiet-time $(K p \leq 3)$ average zonal drifts (positive eastward) measured by DE-2 during 1982. The scatter bars denote the standard deviations.

nal profiles derived by Scherliess (1997) from lower altitude $(300 \mathrm{~km}) \mathrm{DE}-2$ IDM data. The lowest latitude $\left(\Lambda=15^{\circ}\right)$ drifts are also in good agreement with Jicamarca radar observations (e.g., Fejer et al., 2005).

Figure 3 shows the local time dependence of the longitudinally averaged zonal drifts in 5 latitudinal sectors. In this case, we smoothed the data using three point running averages weighted by the standard deviations. Since local time and season were locked together in the DE-2 measurements, the drifts at different local times sectors correspond to different seasons. The large standard deviation at 10:30 LT results from a DC offset in the 1981 data, which required a $50 \mathrm{~m} / \mathrm{s}$ correction. Figure 3 indicates that our highest latitude drifts are westward with typical magnitudes of about $30-50 \mathrm{~m} / \mathrm{s}$, except in the morning-noon period when they first decrease in magnitude, and then briefly reverse to eastward. The low 
2554J. W. Jensen and B. G. Fejer: Longitudinal dependence of middle and low latitude zonal plasma drifts measured by DE-2

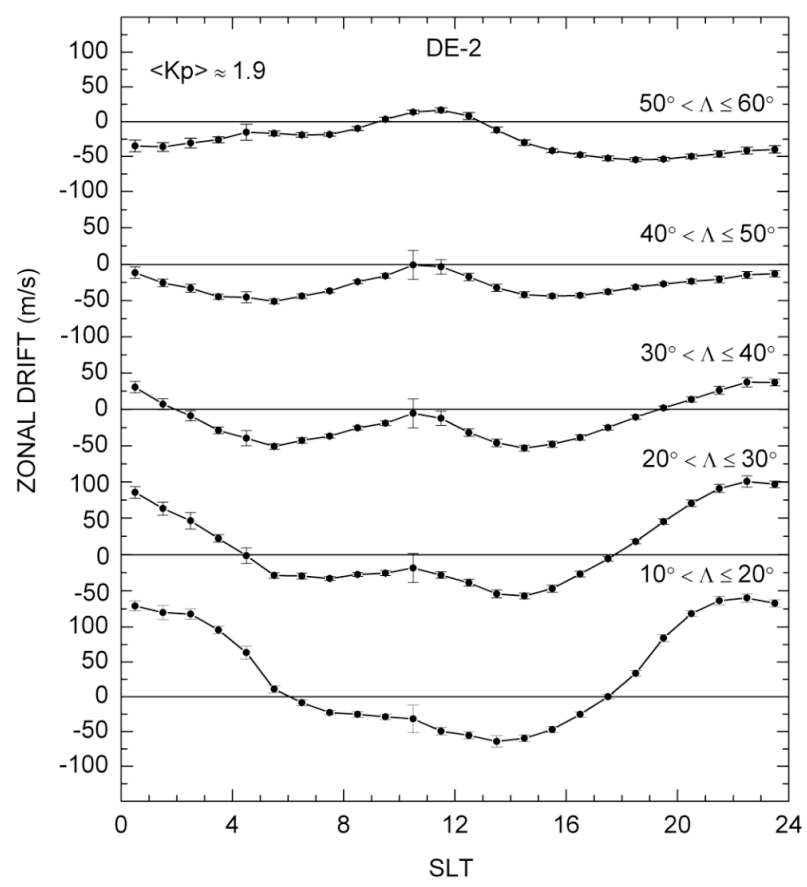

Fig. 3. Longitudinally averaged quiet-time DE-2 zonal drift velocities in five latitudinal sectors.

latitude $\left(\Lambda<30^{\circ}\right)$, the drifts are westward during the day with typical values of $40 \mathrm{~m} / \mathrm{s}$, and eastward at night with largest values (up to about $170 \mathrm{~m} / \mathrm{s}$ ) in the premidnight sector. These latitudinal profiles are in good agreement with the results presented by Heelis and Coley (1992) and, at the lowest latitudes, they are also in good agreement with the Jicamarca drifts (Fejer et al., 2005)

\subsection{Longitudinal dependence}

The DE-2 zonal drift database is not extensive enough for the study of longitudinal variations in hourly periods. Therefore, we examined this dependence using $4 \mathrm{~h}$ local time bins to improve the statistical significance of our results, which still allowed us to largely decouple longitudinal and seasonal effects. Initially, we have determined the relative zonal drifts by subtracting from each measurement the corresponding longitudinally averaged hourly value. Then, we determined the longitudinal variation of the relative drifts using $4 \mathrm{~h}$ local time bins, $10^{\circ}$ latitudinal bins, and $60^{\circ}$ overlapping longitudinal bins centered $30^{\circ}$ apart, with periodic boundary conditions. We should note that these residual drifts are more accurate than the absolute values, since instrumental offsets should be subtracted out through this procedure.

Figure 4 shows the longitudinal variation of the quiet-time $(K p \leq 3)$ northern and southern hemisphere relative drifts during 20:00-24:00 LT, which corresponds to equinoctial conditions. In this case, the standard deviations of the mean

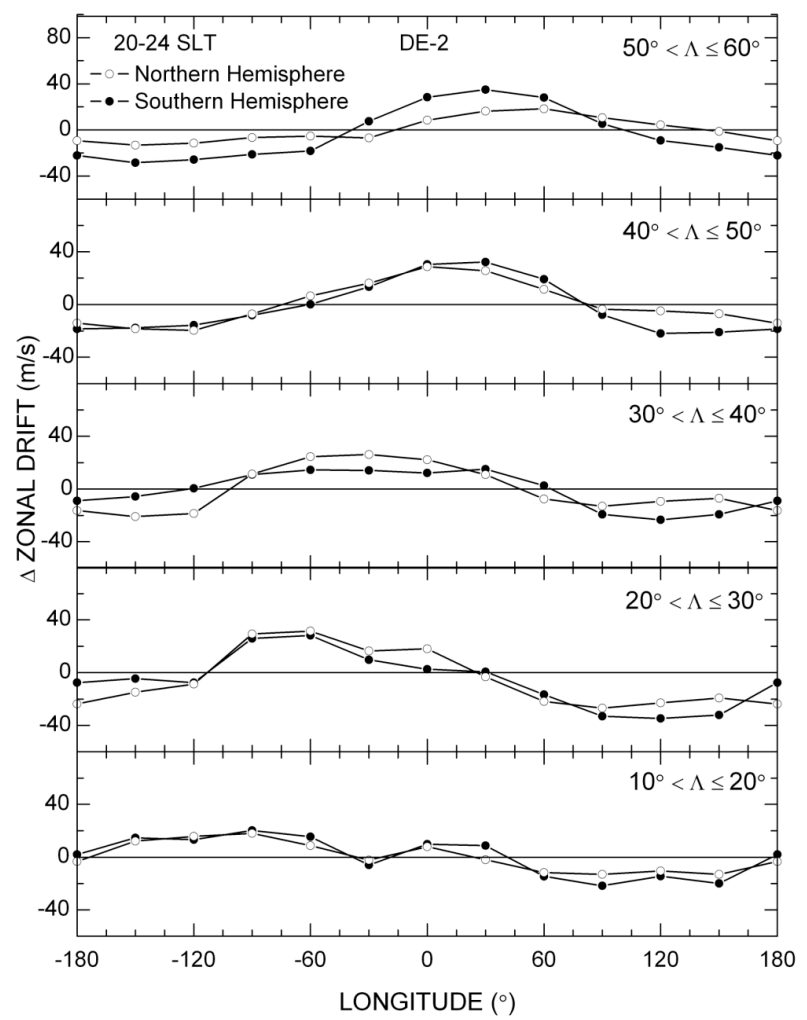

Fig. 4. Longitudinal variations of early night northern and southern hemisphere quiet-time average relative zonal drift velocities in five longitudinal sectors.

varied from about $10 \mathrm{~m} / \mathrm{s}$ at $55^{\circ}$ to about $30 \mathrm{~m} / \mathrm{s}$ at $15^{\circ}$. Figure 4 indicates that the largest relative drifts occur between about $-10^{\circ}$ and $70^{\circ}$ at upper middle latitudes, and from $-150^{\circ}$ to $-60^{\circ}$ at low latitudes. The peak to peak values are about $40-50 \mathrm{~m} / \mathrm{s}$. Notice that, as shown in Fig. 3, in this local time sector the longitudinally averaged drifts are westward at upper mid-latitude drifts and eastward at low latitudes. Figure 5 illustrates in more detail the good agreement of the northern and southern hemisphere data. In this case, we have used 13 normalized cubic b-splines at equally spaced nodes for each latitudinal bin, and interpolated the resulting data to generate a grid of 20 points in latitude by 20 in longitude. This figure shows the interpolated data down to invariant latitudes of $10^{\circ}$ even though our data were restricted to higher latitudes, as shown in Fig. 2.

We have seen in Fig. 2 that the northern and southern hemisphere longitudinally averaged drifts are in good agreement, and in Figs. 4 and 5 that the same is true for their longitudinal variations during the 20:00-24:00 local time period. The patterns from both hemispheres were consistent also during the other $4 \mathrm{~h}$ local time periods; therefore, from now on, we show only results obtained by combining the data from both hemispheres, which further improves their statistical significance. 


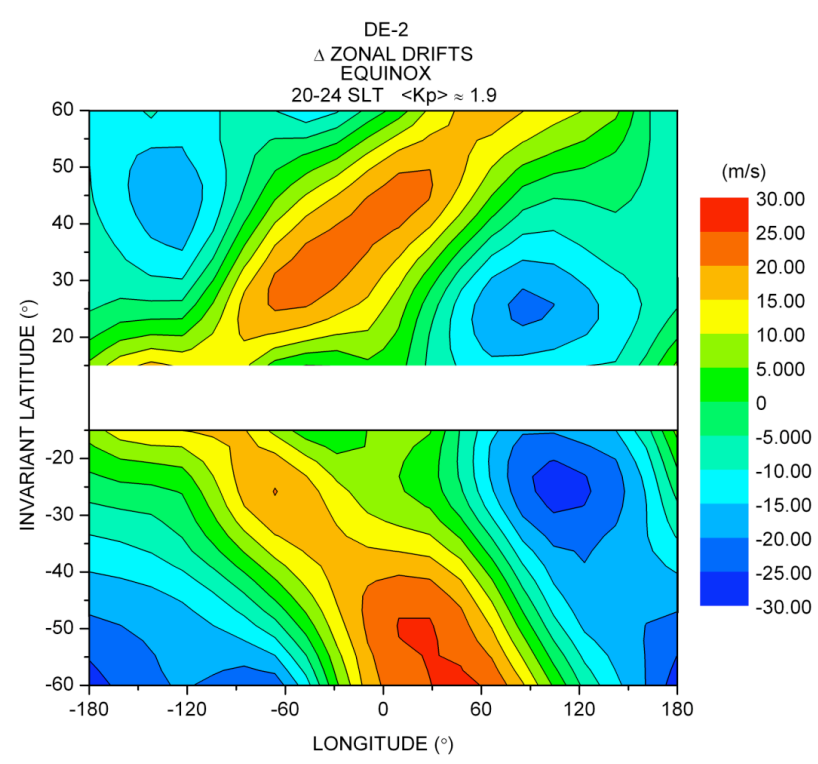

Fig. 5. Longitudinal and latitudinal dependence of average quiettime relative zonal plasma drifts in the early night sector.

Figure 6 shows in the top panel the longitudinal dependence of the quiet-time equinoctial relative drifts in the premidnight sector. The bottom panel shows the estimated latitudinal and longitudinal dependence of the drift velocities at 22:50 LT, obtained by combining the hourly and longitudinally averaged drifts given in Fig. 3, and the longitude dependent relative drifts given in the top panel. At this local time, the drifts are westward at upper middle latitudes, with smallest magnitudes near $60^{\circ} \mathrm{E}$; they change to eastward at $\Lambda=45^{\circ}$ near $30^{\circ} \mathrm{E}$, and at $\Lambda=40^{\circ}$ near $180^{\circ} \mathrm{E}$. The low latitude eastward drifts have largest values (up to about $180 \mathrm{~m} / \mathrm{s}$ ) between about $30^{\circ}$ and $120^{\circ} \mathrm{W}$. The latitudinal variations of these early night drifts are strongest (weakest) near $150^{\circ} \mathrm{W}$ $\left(150^{\circ} \mathrm{E}\right)$. The zonal drifts shown in the bottom panel of Fig. 6 are in good agreement with results from middle, low latitude and equatorial radar drift measurements (e.g., Fejer, 1993; Scherliess et al., 2001; Fejer et al., 2005).

We have seen in Fig. 1 that the number of measurements during 00:00-04:00 LT, which correspond to June and December solstice, was relatively small. Therefore, in this case, we have averaged the data from these two seasons. The resulting the longitudinal dependence is generally similar to that shown in Fig. 4, but shifted eastward by about $80^{\circ}$, and with smaller peak to peak variations.

The most extensive DE- 2 drift measurements were made during the 20:00-24:00 and 04:00-08:00 LT. The latter period, which corresponded to the solstices, is the only one with large enough number of measurements for the study of longitudinal effects during different seasons. In this case, the June solstice data are almost exclusively from 1982, while the December solstice data are mostly from 1981 and 1982.

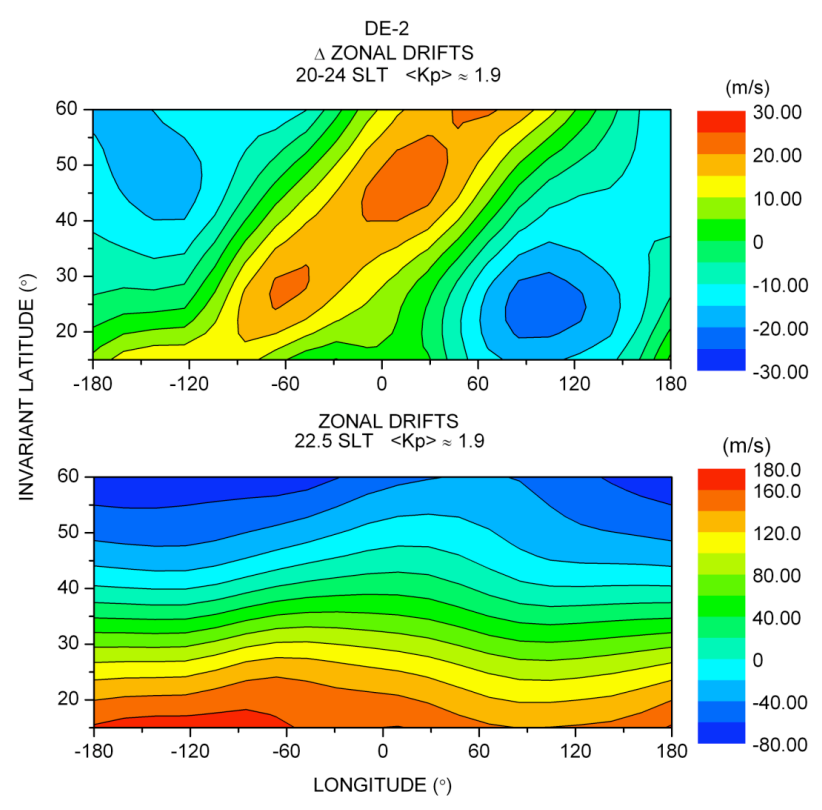

Fig. 6. Latitudinal and longitudinal dependence of relative zonal drifts (positive eastward) obtained by averaging the northern and southern hemisphere quiet-time relative drifts (upper panel). Latitudinal and longitudinal variations of the zonal drift velocities obtained by adding the relative drifts shown in the upper panel and the longitudinally averaged values at 22.5 LT (lower panel).

We have determined the longitudinal variation of the relative drifts during this period using the same procedure outlined earlier. Figure 7 shows that during this early morning period the longitudinal variations of the June and December solstice residual drifts are mostly anti-correlated. During December solstice, the largest relative drifts occur at about $30^{\circ} \mathrm{E}$ at higher latitudes, and near $90^{\circ} \mathrm{W}$ at low latitudes, while during June solstice they occur at about $90^{\circ} \mathrm{W}$ and $120^{\circ} \mathrm{E}$, respectively. The peak-to-peak variations of these drifts are about $40 \mathrm{~m} / \mathrm{s}$.

Figure 8 shows the derived longitudinal variations of the zonal drifts at 05:30 LT, obtained by adding the longitudinally averaged and corresponding longitude dependent relative drifts for the solstices. Notice that the zonal drifts at 05:30 LT shown in Fig. 3, are longitudinal averages of the corresponding June and December solstice values. Figure 8 shows that the December solstice drifts are westward at middle latitudes with largest magnitudes (about $75 \mathrm{~m} / \mathrm{s}$ ) near $15^{\circ} \mathrm{E}$ and eastward at the lowest latitudes. During June solstice the region of westward drifts is shifted about $5^{\circ}$ equatorward, with maximum values (about $55 \mathrm{~m} / \mathrm{s}$ ) near $170^{\circ} \mathrm{E}$; the higher (lower) latitude drifts are eastward with larger (lower) values than during December. Late night-early morning radar observations show larger westward drifts during December solstice than during June solstice over Arecibo (Fejer, 1993) and opposite results over the MU radar (Takami et al., 1996), in good agreement with the results presented in Fig. 8. 
2556J. W. Jensen and B. G. Fejer: Longitudinal dependence of middle and low latitude zonal plasma drifts measured by DE-2

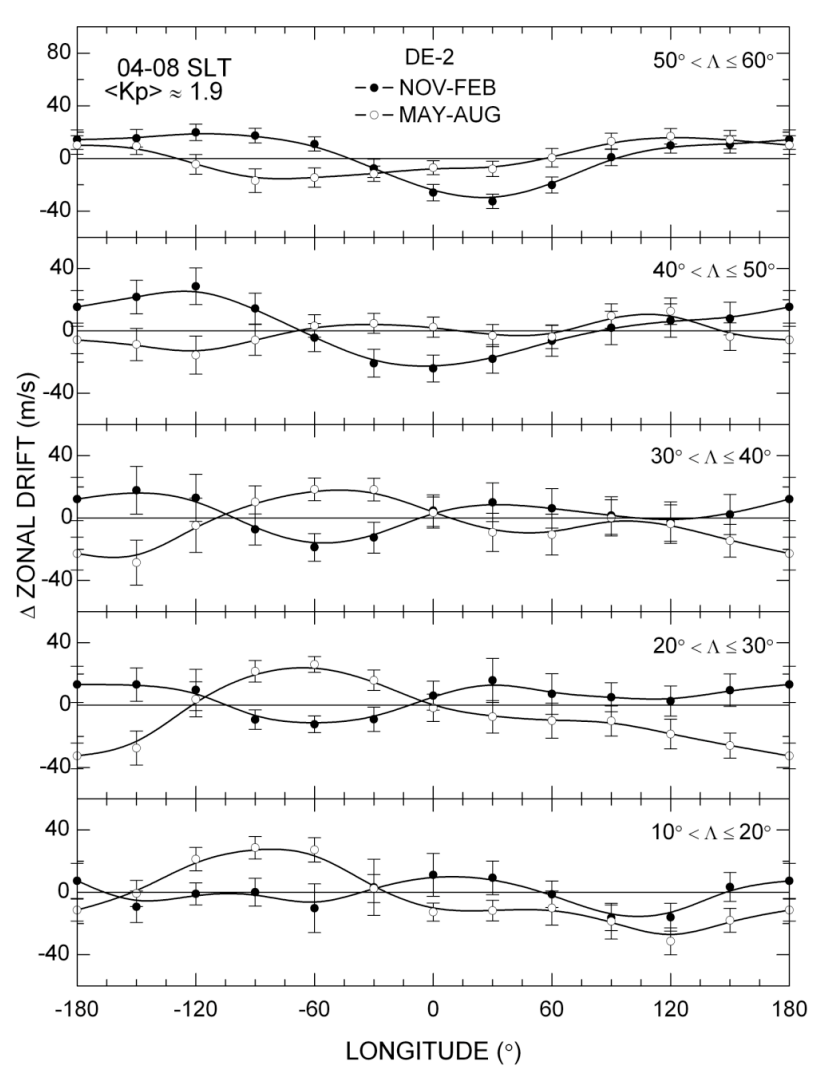

Fig. 7. Longitudinal variation of the late night-early morning quiettime relative zonal drifts during June and December solstice in five longitudinal sectors.

The longitudinal dependence of the relative zonal drifts during 08:00-12:00 LT is approximately anti-correlated to that during 20:00-24:00 LT shown in Fig. 4, but with peak to peak values about half as large. In the 12:00-16:00 LT period the relative zonal drifts have only small magnitudes and longitude dependence. Finally, in the 16:00-20:00 LT period, the longitudinal variation of the relative drifts resembles that of the 20:00-20:00 LT period shown in Fig. 4 but with smaller magnitudes, since this period also includes daytime drifts.

\section{Disturbed drifts}

Figure 9 shows the latitudinal variation of the longitudinally averaged quiet and disturbed drifts now as a function of magnetic local time. For $\Lambda>50^{\circ}$, the disturbance (difference between disturbed and quiet time) drifts are eastward from about 02:00 to 12:00 MLT, and westward at other local times. These westward drifts are largest near 20:00 MLT, where they reach average values of about $300 \mathrm{~m} / \mathrm{s}$ for $K p \sim 5$. At the lower latitudes, the perturbation drifts are westward at all local times, and have largest values near midnight for

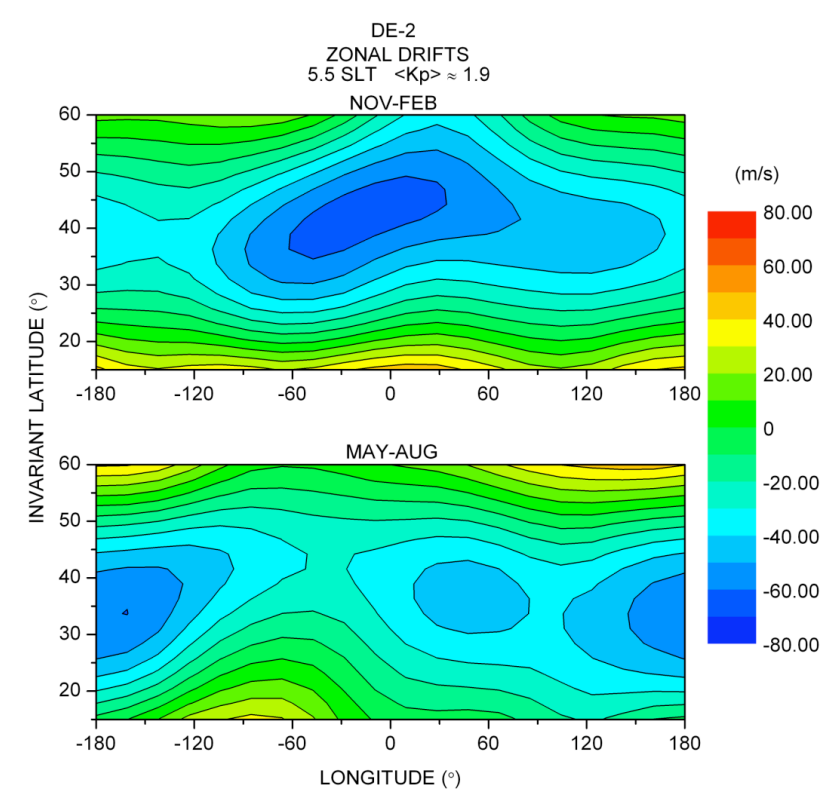

Fig. 8. Latitudinal and longitudinal dependence of quiet-time zonal drifts at 5.5 LT during December and June solstice.

$30^{\circ}<\Lambda<50^{\circ}$ and in the postmidnight sector at the lowest latitudes; the daytime disturbance drifts are very small.

The results shown in Fig. 9 are in good agreement with the DE-2 drift patterns presented by Heelis and Coley (1992) and Scherliess and Fejer (1998). They are also consistent with the middle, low and equatorial perturbation drifts derived from incoherent scatter radar observations (Blanc, 1983; Fejer, 1993, 1997; Scherliess et al., 2001), and with ionosonde derived drifts over Bundoora, Australia $\left(141.1^{\circ} \mathrm{E}\right.$, $37.7^{\circ} \mathrm{S}, 49^{\circ} \mathrm{S}$ magnetic) (Parkinson et al., 2001). These earlier studies have shown that mid-latitude disturbance drifts are largely due to the equatorward extension of auroral electric fields; the lower latitude perturbation drifts are mostly due to prompt penetration and disturbance dynamo electric fields.

We have seen that the largest middle latitude perturbation drifts occur near 21:00 MLT. Figure 10 shows the longitudinal dependence of the quiet and disturbed drifts in the 18:0022:00 MLT sector for $50^{\circ}<\Lambda \leq 60^{\circ}$. This figure shows that for $60 \geq \Lambda>50^{\circ}$ the European sector has the smallest westward drifts during quiet times, but the largest during geomagnetic active periods. For $50^{\circ}>\Lambda>40^{\circ}$, the magnitudes of the disturbed drifts are significantly smaller, but they are still largest in the European sector. Similar results were obtained in the 19:00-23:00 and 20:00-24:00 MLT sectors. The longitudinal dependence of the low latitude drifts, which are eastward with largest magnitudes between 22:00-04:00 MLT, cannot be inferred from our data.

The DE-2 satellite often measured very large westward drifts in the late afternoon - midnight sector. Figure 11 shows 
J. W. Jensen and B. G. Fejer: Longitudinal dependence of middle and low latitude zonal plasma drifts measured by DE-2557

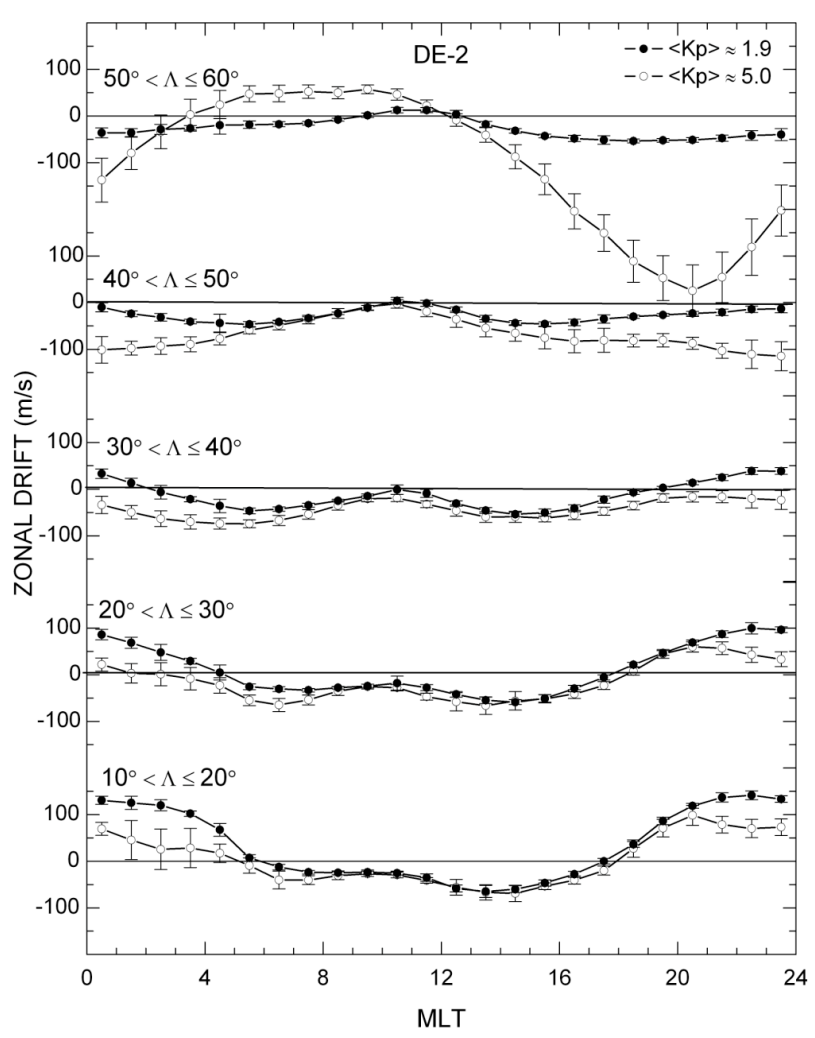

Fig. 9. Longitudinally averaged zonal drift velocities during geomagnetically quiet $(K p \leq 3)$ and disturbed $(K p>4)$ conditions.

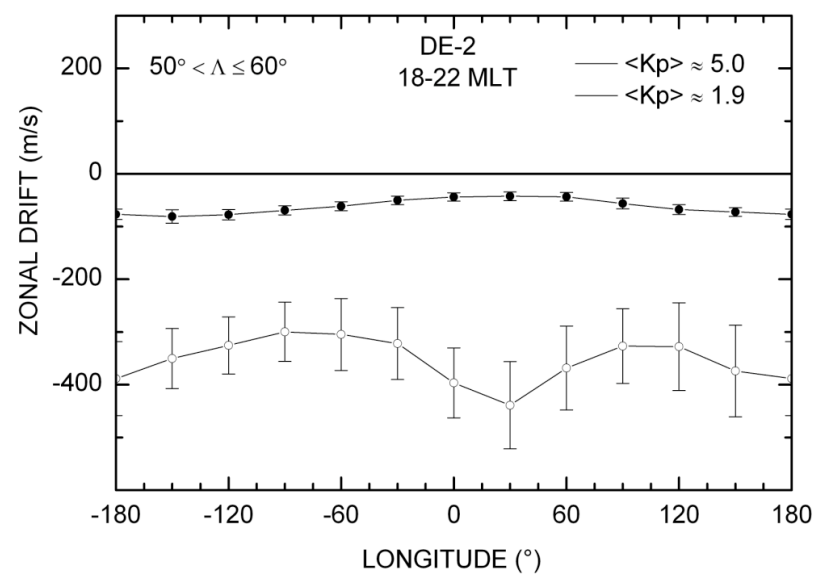

Fig. 10. Longitudinal dependence of quiet $(K p \leq 3)$ and disturbed $(K p>4)$ zonal drifts velocities at upper middle latitudes. The scatter bars denote the standard deviations.

the percentage of occurrence of very large westward drifts for $K p>4$ in the 18:00-22:00 MLT sector. The total number of drift measurements with $K p>4$ in each of the two latitudinal bins shown in Figure 11 was about 2000; the number of data points with westward drifts larger than $600(800) \mathrm{m} / \mathrm{s}$ was 411 (259) in the higher latitudinal bin and 110 (74) in the

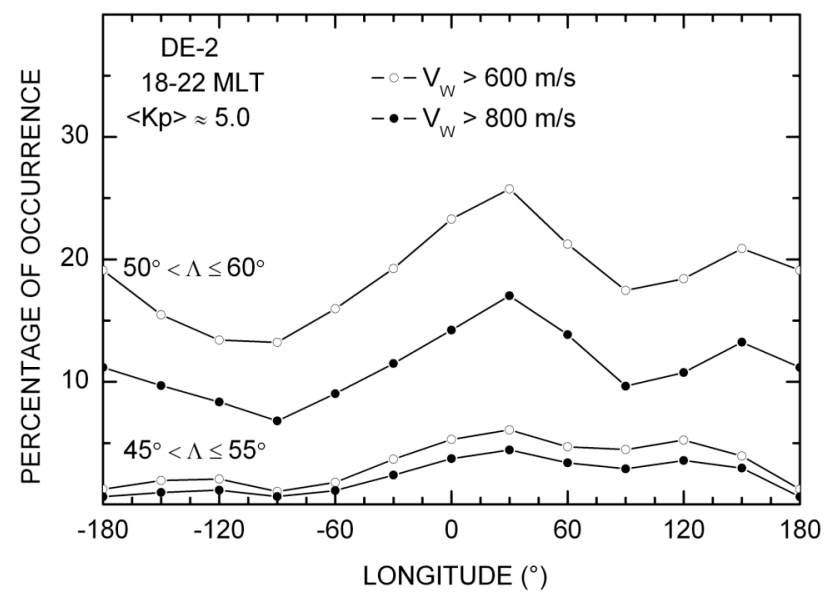

Fig. 11. Percentage of occurrence of early night large westward drifts at upper middle latitudes for $K p>4$.

lower one. This Figure shows a large peak in the European sector, a secondary peak at about $150^{\circ} \mathrm{E}$; and a broad minimum in the Pacific sector in the upper latitudinal bin, and the sharp decrease in the frequency of occurrence of these large velocities with latitude. The 19:00-23:00 MLT data showed similar longitudinal dependence, but with smaller frequencies of occurrence, and the 20:00-24:00 MLT data showed a large decrease in the frequency of occurrence in the European sector and again a significantly larger occurrence at eastern longitudes than at westerns longitudes.

Assuming that the extension of auroral convection velocities to lower latitudes should generally be longitude independent, these data suggest that the frequency of occurrence of SAPS events during equinox should be highest in the European sector. The 2000-2400 data also showed an increase in the occurrence of these large velocities for $45^{\circ}<\Lambda<55^{\circ}$, which is consistent with the increase in the frequency of occurrence of SAPS events at lower latitudes with increasing magnetic local times (Foster and Vo, 2002).

At latitudes below $40^{\circ}$, the disturbed drifts are significantly smaller and so appears to be their longitudinal dependence. The perturbation drifts at these latitudes should mostly be due disturbance dynamo electric fields (e.g., Blanc and Richmond, 1980). Therefore, our results suggest that low latitude disturbance dynamo meridional electric fields do not have strong longitudinal dependence during late afternoon-midnight equinoctial periods.

\section{Summary}

We have studied the latitudinal and longitudinal dependence of the middle and low latitude zonal plasma drifts measured by the DE-2 satellite. Our results indicate significant latitude dependent longitudinal variations of the quiet time drifts from evening to early morning hours at all seasons. The 
quiet-time eastward relative drifts in the premidnight sector are largest in the European sector at upper middle latitudes and in the American - Pacific sector a low latitudes. The longitudinal variations of the late night-early morning relative drifts during June and December solstice are anticorrelated; the daytime drift do not change much with longitude. The zonal perturbations drifts resulting enhanced geomagnetic activity are westward and have largest values in the upper middle latitudes and in the evening and early night periods. During equinox, the upper middle latitude disturbance drifts are largest in the European sector. Our results suggest that during equinox SAPS events occur most often over the European sector. The low latitude disturbance drifts during equinox are largest in the midnight sector and do not appear to have strong longitudinal dependence.

Acknowledgements. This work was supported by the NASA Living With a Star (LWS) Program through grant NNX06AC44G.

Topical Editor M. Pinnock thanks A. Richmond for his help in evaluating this paper.

\section{References}

Anderson, P. C., Carpenter, D. L., Tsuruda, K., Mukai, T., and Rich, F. J.: Multisatellite observations of rapid subauroral ion drifts (SAID), J. Geophys. Res., 106, 29 585-29 599, 2001.

Blanc, M.: Magnetospheric convection effects at mid-latitudes, J. Geophys. Res., 88, 211-223, 1983.

Blanc, M. and Richmond, A. D.: The ionospheric disturbance dynamo, J. Geophys. Res, 85, 1669-1686, 1980.

Buonsanto, M. J. and Witasse, O. G.: An updated climatology of thermospheric winds and $\mathrm{F}$ region ion drifts over Millstone Hill, J. Geophys. Res., 104, 24 675-24 687, 1999.

Burke, W. J., Rubin, A. G., Maynard, N. C., Gentile, L. C., Sultan, P. J., Rich, F. J., Beaujardiere, O. de la, Young, C. Y., and Wilson, G. R.: Ionospheric disturbances observed by DMSP at middle to low latitudes during the magnetic storm of June 4-6, 1991, J. Geophys. Res., 105, 18 391-18 405, 2000.

Coley, W. R. and Heelis, R. A.: Low latitude zonal and vertical ion drifts seen by DE 2, J. Geophys. Res., 94, 6751-6761, 1989.

Coley, W. R., Heelis, R. A., and Spencer, N. W.: Comparison of low-latitude ion and neutral zonal drifts using DE-2, J. Geophys. Res., 99, 341-348, 1994.

Fejer, B. G.: Low latitude electrodynamic plasma drifts, J. Atmos. Terr. Phys., 53, 677-693, 1991.

Fejer, B. G.: F-Region plasma drifts over Arecibo: Solar cycle, seasonal, and magnetic activity effects, J. Geophys. Res., 98, 13 645-13 652, 1993.

Fejer, B. G.: The electrodynamics of the low latitude ionosphere: Recent results and future challenges, J. Atmos. Sol.-Terr. Phy., 59, 1456-1482, 1997.

Fejer, B. G. and Scherliess, L.: Mid- and low-latitude prompt penetration ionospheric zonal plasma drifts, Geophys. Res. Lett., 25, 3071-3074, 1998.

Fejer, B. G., Souza, J. R., Santos, A. S., and Perreira, A. E. C.: Climatology of F region zonal drifts over Jicamarca, J. Geophys. Res., 110, A12310, doi:10.1029/2005JA011324, 2005
Foster, J. C. and Burke W. J.: SAPS: A new characterization for subauroral electric fields, EOS Trans. AGU, 83, 393-394, 2002.

Foster, J. C. and Vo, H. B.: Average characteristics and activity dependence of the subauroral polarization stream, J. Geophys. Res., 107, 1474, doi:10.1029/2002JA009409, 2002.

Foster, J. C., Erickson, P. J., Coster, A. C., Goldstein, J., and Rich, F. J.: Ionospheric signatures of plasmaspheric tails, Geophys. Res. Lett, 29, doi:10.1029/2002JA009409, 2002.

Fukao, S., Oliver, W. S., Onishi, Y., Takami, T., Sato, T., Yamamoto, M., and Kato, S.: F region seasonal behavior as measured by the MU radar, J. Atmos. Terr. Phys., 53, 599-618, 1991.

Galperin, Y., Ponomarev, V. N., and Zosimova, A. G.: Plasma convection in the polar ionosphere, Ann. Geophys., 30, 1-7, 1974, http://www.ann-geophys.net/30/1/1974/.

Galperin, Y. I., Soloviev, V. S., Torkar, K., Foster, J. C., and Veselov, M. V.: Predicting plasmaspheric radial density profiles, J. Geophys. Res., 102, 2079-2091, 1997.

Heelis, R. A. and Coley, W. R.: East-west ion drifts at mid-latitudes observed by Dynamics Explorer 2, J. Geophys. Res., 97, 1946119469, 1992.

Heelis, R. A., Hanson, W. B., Lippincott, C. R., Zuccaro, D. R., Harmon, L. H., Holt, B. J., Doherty J. E., and Power, R. A.: The ion drift meter for the Dynamics Explorer-B, Space Sci. Instrum, 5, 511-521, 1981.

Immel, T. J., Frey, H. U., Mende, S. B., and Sagawa, E.: Global observations of the zonal drift of equatorial plasma bubbles, Global observations of the zonal drift speed of equatorial ionospheric plasma bubbles, Ann. Geophys., 22, 3099-3107, 2004, http://www.ann-geophys.net/22/3099/2004/.

Jacobsen, A. R., Hoogeveen, G., Carlos, R. C., Wu, G., Fejer, B. G., and Kelley, M. C.: Observations of inner plasmasphere irregularities with a satellite-beacon radio-interferometer array, J. Geophys. Res., 101, 19665-19682, 1996.

Kelley, M. C.: The Earth's ionosphere, Academic, New York, 1989.

Martinis, C., Eccles, J. V., Baumgardner, J., Manzano, J., and Mendillo, M.: Latitude dependence of zonal plasma drifts obtained from dual-site airglow observations, J. Geophys. Res., 108, 1129, doi:10.1029/2002JA009462, 2003.

Oliver, W. L., Yamamoto, Y., Takami, T., Fukao, S., Yamamoto, M., and Tsuda, T.: Middle and upper atmosphere radar observations of ionospheric electric fields, J. Geophys. Res., 98, 11 615$11627,1993$.

Parkinson, M. L., Polglase, M., Fejer, B. G., Scherliess, L., P. L. Dyson, P. L., and Ujmaia, S. M.: Seasonal and magnetic activity variations of ionospheric electric fields above the southern midlatitude station Bundoora $\left(145.1^{\circ} \mathrm{E}, 37.7^{\circ} \mathrm{S}\right.$, geographic; $49^{\circ} \mathrm{S}$ magnetic), Ann. Geophys. 19, 521-532, 2001.

Richmond, A. D.: Ionospheric electrodynamics, in: Handbook of Atmospheric Electrodynamics, 2, edited by: Volland, H., CRC Press, Boca Raton, FL., 249-290, 1995.

Scherliess, L.: Empirical studies of ionospheric electric fields, $\mathrm{PhD}$ Thesis, Utah State Univ., Logan, Utah, 1997.

Scherliess, L. and Fejer, B. G., Satellite studies of mid- and lowlatitude ionospheric disturbance zonal plasma drifts, Geophys. Res. Lett., 25, 3071-3073, 1998.

Scherliess, L., Fejer, B. G., Holt, J., Goncharenko, L., ArmoryMazaudier, C., and Buonsanto, M. J.: Radar studies of midlatitude ionospheric plasma drifts, J. Geophys. Res., 106, 1171$1183,2001$. 
J. W. Jensen and B. G. Fejer: Longitudinal dependence of middle and low latitude zonal plasma drifts measured by DE-2559

Sheehan, R. E. and Valladares, C. E.: Equatorial ionospheric zonal drift model and vertical drift statistics from UHF scintillation measurements in South America, Ann. Geophys. 22, 317733193, 2004.

Sobral, J. H. A., Abdu, M. A., Takahashi, H., Sawant, H., Zamlutti, C. J., and Borba G. L.: Solar and geomagnetic effects on nocturnal zonal velocities of ionopheric plasma depletions, Adv. Space Res., 24(11), 1507-1510, 1999.
Takami, T., Oliver, W. L., Richmond, A. D., and Fukao, S.: Ionospheric drift similarities at magnetic conjugate and nonconjugate locations, J. Geophys. Res., 101, 15773-15 782, 1996. 